\title{
BMJ Open Rate of normal lung function decline in ageing adults: a systematic review of prospective cohort studies
}

\author{
Elizabeth T Thomas, ${ }^{\oplus 1,2}$ Michelle Guppy, ${ }^{\circledR 1,3}$ Sharon E Straus, ${ }^{4,5}$ Katy J L Bell, ${ }^{\oplus 1,6}$ \\ Paul Glasziou ${ }^{\circledR 1}$
}

To cite: Thomas ET, Guppy M, Straus SE, et al. Rate of normal lung function decline in ageing adults: a systematic review of prospective cohort studies. BMJ Open 2019;9:e028150. doi:10.1136/ bmjopen-2018-028150

- Prepublication history and additional material for this paper are available online. To view please visit the journal (http:// dx.doi.org/10.1136/bmjopen2018-028150).

Received 23 November 2018 Revised 1 March 2019 Accepted 14 May 2019

\section{Check for updates}

(C) Author(s) (or their employer(s)) 2019. Re-use permitted under CC BY-NC. No commercial re-use. See rights and permissions. Published by BMJ.

${ }^{1}$ Institute for Evidence-Based Healthcare, Faculty of Health Sciences and Medicine, Bond University, Gold Coast, Queensland, Australia

${ }^{2}$ Gold Coast University Hospital, Southport, Queensland, Australia ${ }^{3}$ School of Rural Medicine, University of New England, Armidale, New South Wales, Australia

${ }^{4}$ Department of Medicine, University of Toronto, Toronto, Ontario, Canada

${ }^{5}$ Li Ka Shing Knowledge Institute, St. Michael's Hospital, Toronto, Ontario, Canada

${ }^{6}$ Sydney School of Public Health, Sydney Medical School, University of Sydney, Sydney, New South Wales, Australia

Correspondence to Dr Elizabeth T Thomas; ethomas@bond.edu.au

\section{ABSTRACT}

Objective To conduct a systematic review investigating the normal age-related changes in lung function in adults without known lung disease.

Design Systematic review.

Data sources MEDLINE, Embase and Cumulative Index to Nursing and Allied Health Literature (CINAHL) were searched for eligible studies from inception to February 12 , 2019, supplemented by manual searches of reference lists and clinical trial registries.

Eligibility criteria We planned to include prospective cohort studies and randomised controlled trials (control arms) that measured changes in lung function over time in asymptomatic adults without known respiratory disease.

Data extraction and synthesis Two authors independently determined the eligibility of studies, extracted data and assessed the risk of bias of included studies using the modified Newcastle-0ttawa Scale. Results From 4385 records screened, we identified 16 cohort studies with 31099 participants. All included studies demonstrated decline in lung function-forced expiratory volume in $1 \mathrm{~s}\left(\mathrm{FEV}_{1}\right)$, forced vital capacity (FVC) and peak expiratory flow rate (PEFR) with age. In studies with longer follow-up ( $>10$ years), rates of $\mathrm{FEV}_{1}$ decline ranged from 17.7 to $46.4 \mathrm{~mL} /$ year (median $22.4 \mathrm{~mL} /$ year). Overall, men had faster absolute rates of decline (median $43.5 \mathrm{~mL} /$ year) compared with women (median $30.5 \mathrm{~mL}$ / year). Differences in relative $\mathrm{FEV}_{1}$ change, however, were not observed between men and women. $\mathrm{FEV}_{1} / \mathrm{FVC}$ change was reported in only one study, declining by $0.29 \%$ per year. An age-specific analysis suggested the rate of FEV function decline may accelerate with each decade of age. Conclusions Lung function-FEV 1 , FVC and PEFRdecline with age in individuals without known lung disease. The definition of chronic airway disease may need to be reconsidered to allow for normal ageing and ensure that people likely to benefit from interventions are identified rather than healthy people who may be harmed by potential overdiagnosis and overtreatment. The first step would be to apply age, sex and ethnicity-adjusted

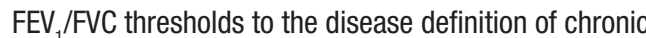
obstructive pulmonary disease.

PROSPERO registration number CRD42018087066.

\section{INTRODUCTION}

In 2016, the WHO estimated that chronic obstructive pulmonary disease (COPD)

\section{Strengths and limitations of this study}

This is the first review to provide estimates for the median decline in spirometry measures including the forced expiratory volume in $1 \mathrm{~s}\left(\mathrm{FEV}_{1}\right)$, forced vital capacity (FVC) and the $\mathrm{FEV}_{1} / \mathrm{FVC}$ ratio based on longitudinal data.

- We used a modified version of the NewcastleOttawa Scale to assess risk of bias.

> The review may be prone to volunteer bias, and therefore may underestimate lung function decline among asymptomatic people.

- Only one study specifically reported the change of the FEV/FVC ratio with age, and we did not have access to unpublished individual participant data to allow calculation of the $\mathrm{FEV}_{1} / \mathrm{FVC}$ ratio change where this was not reported.

affected 251 million people worldwide, with its prevalence continuing to rise with an ageing population. ${ }^{1}$ Current guidelines in $\mathrm{UK}^{2}$ Australasia, ${ }^{3}$ Europe and the $\mathrm{USA}^{4}$ recommend that COPD is diagnosed if an individual has symptoms such as dyspnoea or sputum production, if they have known risk factors such as smoking or biomass fuel exposure and if they demonstrate post-bronchodilator airflow limitation on spirometry. Airflow limitation on spirometry is defined when the ratio of forced expiratory volume in $1 \mathrm{~s}\left(\mathrm{FEV}_{1}\right)$ to forced vital capacity (FVC) is less than $70 \%$ after bronchodilator administration. ${ }^{23}$ However, this arbitrary diagnostic threshold has attracted criticism as it does not adjust for age or sex. ${ }^{5-10}$

Ageing is invariably accompanied by changes in lung function due to factors such as loss of lung elasticity, weakened muscles of respiration, and decreased surface area for alveolar gas exchange. Several published cross-sectional studies ${ }^{911-13}$ and longitudinal studies $^{1415}$ report that lung function parameters such as FEV 1 and FVC decline with age.

The 2018 update of the Global Initiative for Chronic Obstructive Lung Disease (GOLD) 
criteria ${ }^{16}$ continues to suggest the use of the fixed ratio rather than an FEV 1 or FVC that lies outside of the lower limit of normal (LLN) range. While the fixed ratio threshold may be simple for clinicians to use, it does not consider that lung function measurements may change with age and vary with gender and ethnicity. Many laboratory tests already have different reference range values for different ages and electronic spirometry machines do the same. The GOLD criteria acknowledge that this arbitrary fixed threshold may overdiagnose normal healthy older adults as diseased and underdiagnose some younger people with disease as healthy. ${ }^{17} 18$

Longitudinal studies need to be identified so that normal changes in lung function can be calculated for different ages. Monitoring change could be used in practice to complement a single time point measurement to identify people who are not within the expected normal range. We aimed to perform a systematic review of prospective cohort studies and randomised controlled trials that examined changes in lung function with age in asymptomatic individuals with no known lung disease who have never smoked. This knowledge would enable further work to develop age-specific, sex-specific and ethnicity-specific estimates that may be especially useful in a primary care setting. This implies that people are only diagnosed with COPD if their spirometry measurements fall outside of the normal range for their age, sex and ethnicity, rather than on the basis of a fixed value.

\section{METHODS}

\section{Protocol registration}

The protocol for this review was drafted in accordance with the Preferred Reporting Items for Systematic Reviews and Meta-Analyses (PRISMA) statement and the Meta-analyses of Observational Studies in Epidemiology (MOOSE) reporting guidelines. It was registered on PROSPERO and is available from http://www.crd.york.ac.uk/PROSPERO/display_record.php?ID=CRD42018087066, see online supplementary file 1 .

\section{Search strategy and inclusion criteria}

We conducted electronic searches of MEDLINE, EMBASE and Cumulative Index to Nursing and Allied Health Literature (CINAHL) databases from inception through to February 2019, using the search strategy specified in online supplementary file 2 . This was developed with an information specialist. Electronic searches were complemented by manual searching through reference lists of studies that were identified for potential inclusion as well as backward and forward searching. We also searched the WHO Clinical Trials registry and ClinicalTrials.gov registries using the key words "normal ageing", "lung function decline", "FEV1 decline", "FVC decline" and "lung decline".

We included cohort studies and also planned to include the control arms of randomised controlled trials that measured the decline of lung function in an ageing population. The inclusion criteria were:

- Longitudinal studies that followed some or all of the adult participants past the age of 65 years.

- Three or more measurements of lung function undertaken.

- Studies with a follow-up period of 3 years or longer.

- Studies that measure lung function (ie, $\mathrm{FEV}_{1}, \mathrm{FVC}$, peak expiratory flow rate (PEFR)).

We excluded studies if the participants did not meet the prespecified age criteria; if the population of interest were reported to include smokers or those with risk factors such as occupational inhalation; if participants were reported to have respiratory symptoms such as wheeze, dyspnoea or chronic cough or if the study included participants with known respiratory disease such as asthma or COPD.

\section{Study selection and data extraction}

Two authors (ETT, MG) independently screened the titles and abstracts of studies identified in the initial search for eligibility. Prior to commencing screening, a small subset of 50 titles were screened by the two reviewers as a calibration exercise to check for $>80 \%$ agreement. Similarly, after screening, a calibration exercise was conducted for screening the full texts of the studies and targeting $>80 \%$ agreement. The remaining full texts were retrieved and reviewed independently by the authors to determine eligibility for inclusion. Non-English publications were translated using Google Translate or with the assistance of a translator. Disagreements were resolved by consensus through discussion or with a third reviewer (PG). If there were multiple reports of the same study, the most recent publication with longest length of follow-up was selected for inclusion, and if the two studies had a similar length of follow-up then the study with the largest sample size was included. Two authors independently extracted data from the studies. The Excel data extraction form was piloted using 10 studies prior to data extraction as a calibration exercise to check for adequate agreement $(>80 \%)$ between the reviewers. Any disagreements were resolved by consensus or with a third reviewer. Extracted measures included study setting, year and duration, participant eligibility criteria, sample size, participants demographics (ethnicity, gender, baseline age), any known risk factors or exposures, baseline lung function, lung function measurements, number and frequency of measurements, average length of follow-up and loss to follow-up. We also aimed to report the proportion of the cohort that subsequently developed symptoms or disease during follow-up.

We assessed risk of bias of included studies using the six items of the Newcastle-Ottawa Scale (NOS) ${ }^{19}$ for assessing quality of included cohort studies. Disagreements were resolved by discussion or a third reviewer.

Assessed factors included:

- Representativeness of the exposed cohort (eg, low risk: random selection; high risk: non-random selection for example, volunteer sampling). 
- Ascertainment of exposure-age (eg, low risk: from medical records; high risk: self-reported).

- Demonstration that the outcome of interest was not present at the start of study (eg, low risk: participants were excluded on the basis of demonstrated airflow limitation; high risk: if participants were not screened).

- Assessment of outcome (eg, low risk: spirometry; high risk: subjective measure of lung function).

- Adequate duration of follow-up (eg, low risk: $\geq 3$ years of follow-up; high risk: <3 years of follow-up).

- Adequate follow-up of cohorts (eg, low risk: $<20 \%$ attrition, loss to follow-up explained; high risk: $>20 \%$ attrition, unexplained loss to follow-up).

Studies were assessed as good quality if they had low risk of bias in all six domains, moderate quality if they had low risk of bias in four or five domains and low quality if they had low risk of bias for three or fewer domains.

\section{Statistical analysis}

For each study cohort, we extracted the annual decline rates for each lung function measure. If these were not reported, we calculated crude decline rates for all reported lung function measure by subtracting the final measure from the initial measure and dividing the result by the duration of follow-up. If these data were not available, we determined crude rates of decline from the graphs provided or contacted the study authors for original data. The data were first analysed descriptively using graphs to determine whether it was appropriate to pool the data. For continuous outcomes, the mean difference (MD) (or standardised MD if studies used different measuring scales) and SD were calculated. The data were reported as an annual decline (unit/year). The overall rates of decline and corresponding $95 \%$ CIs were presented in a forest plot. We planned to perform a meta-analysis to pool the estimates of decline.

We presented the data by functional parameter $\left(\mathrm{FEV}_{1}\right.$, $\mathrm{FEV}_{0.75}$, FVC, PEFR) and planned to compare annual decline rates by sex and ethnicity in absolute and relative terms, where data were available. We also extracted and presented age-specific decline rates by decade of age if studies reported these data. We planned to separately analyse the data of those who developed disease during follow-up. We also planned to examine for birth cohort effects if the data were available. Sensitivity analyses were planned for study duration greater than 10 years.

\section{Patient and public involvement}

Patients were not involved in the design, data extraction or data analysis of this review.

\section{RESULTS}

\section{Study characteristics}

From searches of MEDLINE, Embase and CINAHL performed on 12 February 2019, we identified 4331 records. An additional 54 records were identified from

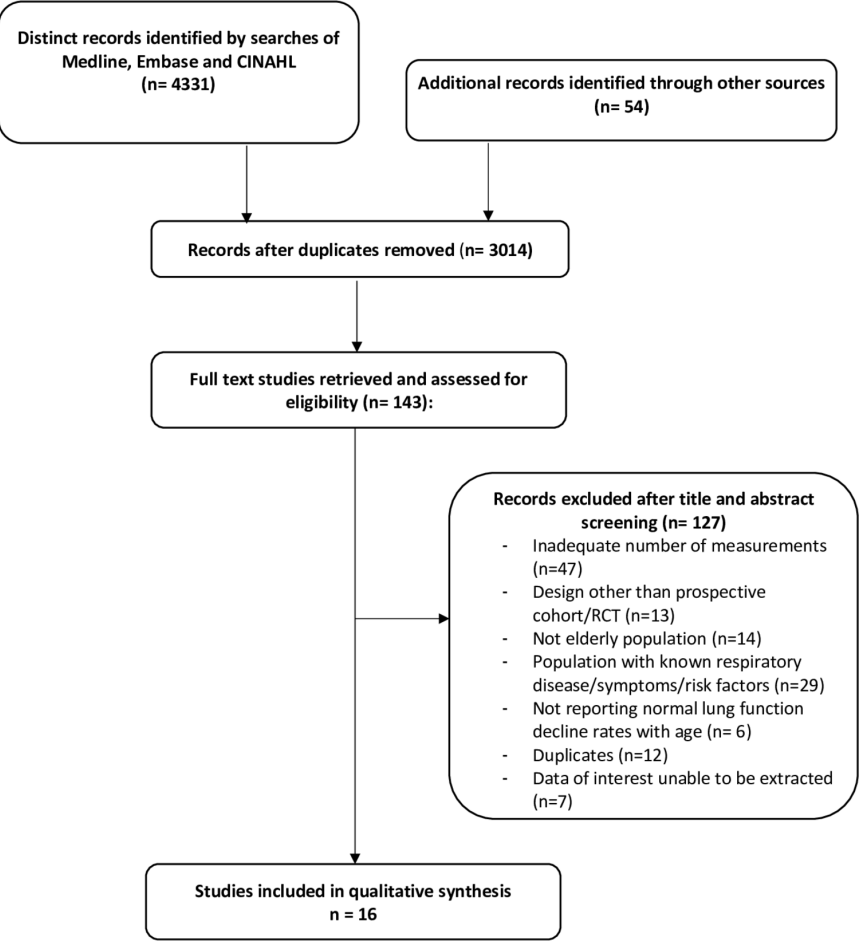

Figure 1 Study flow diagram showing the process for inclusion of prospective randomised controlled trials (RCTs) and cohort studies for estimating the rate of lung function decline with age.

clinical trial registries and reference list searches. From these, we retrieved 143 papers for full text review; 115 of these did not meet our selection criteria and a further 12 were removed as duplicates. In total, 16 studies $^{20-35}$ were included in the systematic review (with one study contributing two data sets ${ }^{29}$ ) (figure 1). The studies included 31099 participants and were conducted between 1959 and 2014 ranging from 5 to 30 years in duration (table 1).

\section{Overall age-related lung function decline}

A meta-analysis was not performed due to substantial heterogeneity across the included studies, and a narrative synthesis was undertaken instead. Thirteen studies reported changes in $\mathrm{FEV}_{1}$ as an outcome. All studies demonstrated a decline with age, with overall rates of decline from each study ranging from 9.9 to $56.0 \mathrm{~mL} /$ year (median $29.2 \mathrm{~mL} /$ year). Seven of these studies examined the differences in rates of decline between males and females, showing greater absolute $\mathrm{FEV}_{1}$ decline in males (median $43.5 \mathrm{~mL} /$ year) than in females (median $30.5 \mathrm{~mL} /$ year) (table 2, figure 2). Relative rates of $\mathrm{FEV}_{1}$ decline were calculated for men in eight studies and for women in six studies that reported baseline $\mathrm{FEV}_{1}$ values. There was no statistically significant difference between men and women's relative change of $\mathrm{FEV}_{1}$ from baseline $(\mathrm{p}=0.7) . \mathrm{FEV}_{0.75}$ decline was reported in one study. ${ }^{29}$ This study provided two data sets (follow-up after 15 years, 30 years) provided in table 2.

Five studies reported changes in FVC, with rate of decline estimates ranging from $14.1 \mathrm{~mL} /$ year in the 


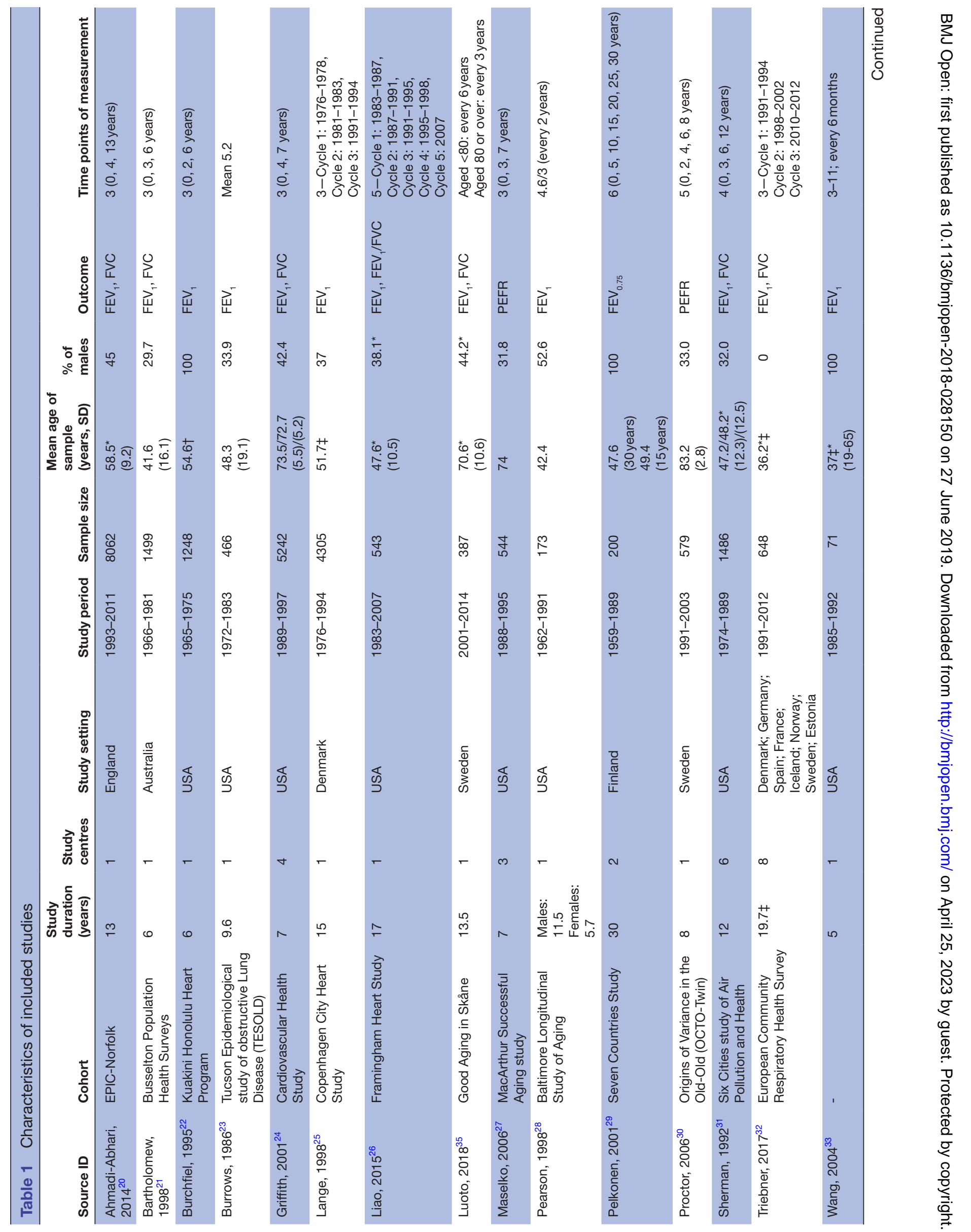


youngest cohort $^{32}$ (median age 36.2 years) to $65.6 \mathrm{~mL} /$ year in the older cohort ${ }^{24}$ (mean age 73.0 years). In studies that measured both $\mathrm{FEV}_{1}$ and FVC over time, there was a greater decline in $\mathrm{FEV}_{1}$ than FVC in two studies, and greater decline in FVC than $\mathrm{FEV}_{1}$ in three studies. These measures are average estimates across study participants and do not enable calculation of individuals' $\mathrm{FEV}_{1} /$ FVCratios. In the one study where individuals' $\mathrm{FEV}_{1} / \mathrm{FVC}$ ratios were reported as an outcome, ${ }^{26}$ there was a decline by $0.29 \%$ per year.

PEFR was reported as an outcome in two studies, ${ }^{27} 30$ which showed decline rates ranging from $-6.6 \mathrm{~L} / \mathrm{min} /$ year in females to $-11.5 \mathrm{~L} / \mathrm{min} /$ year in males.

\section{Age-specific lung function decline by decade of age}

The age-specific rates of $\mathrm{FEV}_{1}$ change by decade of age were extracted or calculated from three studies. ${ }^{22} 232835 \mathrm{In}$ all but one study, estimates of decline increased from the fourth (age 30-40 years) to eighth decades of life (table 3 ). One study could not be included in this comparative analysis as they included smokers and reported decline rates at the end of study follow-up (rather than baseline age) ${ }^{35}$ This study reported that the rates of relative decline increase from the seventh $(-1.7 \%$ /year $)$ through to the tenth decade $(-3.1 \%$ /year $)$, though absolute rates of decline varied. Another study also reported that the rate of decline may be non-linear in multiple regression models of $\mathrm{FEV}_{1}$ and FVC decline (where age squared was also a statistically significant variable).$^{34}$

Two studies examined lung function change within age brackets that did not conform to our decade-specific analysis. Bartholomew and Knuiman ${ }^{21}$ reported greater decline rates in never smokers aged above 45 years (females: $-30.7 \mathrm{~mL} /$ year, males $-45.8 \mathrm{~mL} /$ year) compared with those aged below 45 years (females: $-24.3 \mathrm{~mL} /$ year, males: $-36.8 \mathrm{~mL} /$ year). Lange et $a l^{25}$ compared decline rates in both male and female non-smokers in 20-year age groups. Females aged 60-79 years had the greatest decline rates $(-31.7 \pm 2.1 \mathrm{~mL} /$ year $)$ compared with the $40-59$ age group $(-17.7 \pm 1.4 \mathrm{~mL} /$ year $)$ and the $20-39$ age group which reported an increase of $5.0 \pm 2.7 \mathrm{~mL} /$ year. Similarly, males aged 60-79 years had the greatest decline rates $(-37.1 \pm 3.7 \mathrm{~mL} /$ year $)$ compared with the $40-59$ year age group $(-24.2 \pm 2.6 \mathrm{~mL} /$ year $)$ and the $20-39$ year age group $(-4.6 \pm 4.2 \mathrm{~mL} /$ year $)$.

\section{Overall rates of mortality/symptom/disease development}

Few studies reported these outcomes in an initially asymptomatic, non-smoking population. One study (Proctor et al) ${ }^{30}$ reported $85 \%$ mortality rate in the elderly cohort (age range 79-96) over 8years. Another study (Lange $e t a l)^{25}$ reported that in their study of non-asthmatics, 364 (2\%) patients who did not report having asthma at the beginning of the study, later reported it in follow-up. However, this estimate included smokers. One study (Wang and Petsonk) ${ }^{33}$ performed their analyses on a highly screened population, meaning they excluded participants from all analyses who developed disease or 


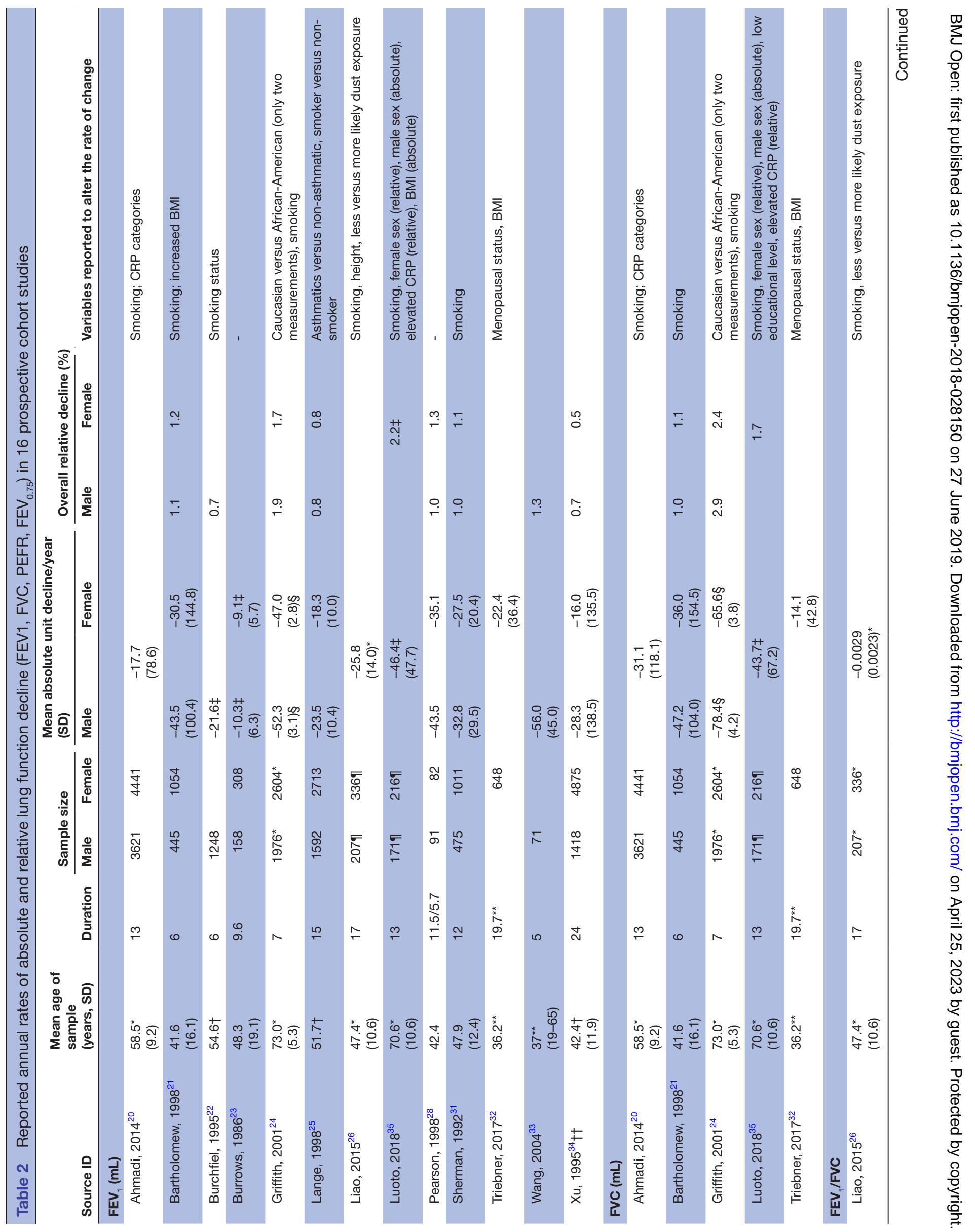




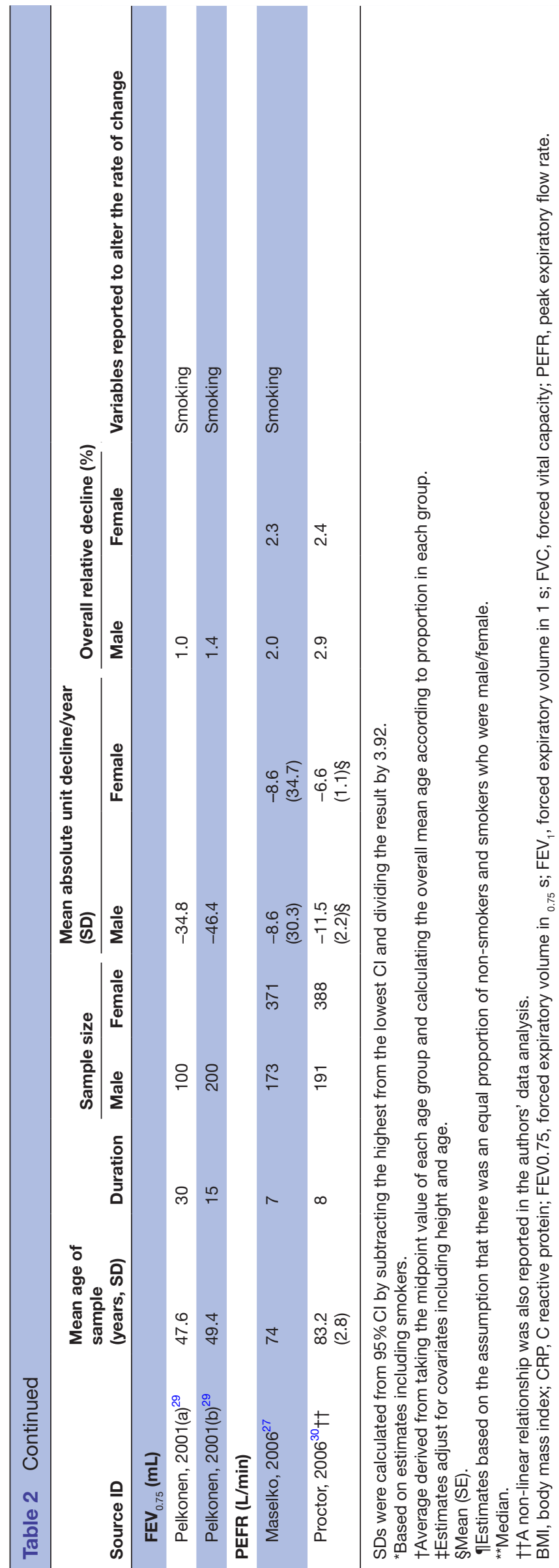

symptoms during study follow-up. No studies reported the rates of lung function change in those who developed disease during the course of the study compared with those who did not.

Sensitivity analyses

$\frac{1}{7}$

\section{(nit}

(

Heterogeneity in study duration was explored in figure 3 . After removing studies with a follow-up of less than 10 years, the median rate of decline of $\mathrm{FEV}_{1}$ was $22.4 \mathrm{~mL} /$ year (figure 4).

Predictors of the rate of decline in lung function in people without known lung disease

Smoking

Although smokers were not included in our main analysis, some studies did compare non-smokers and smokers which we report here. The decline rates were compared in non-smokers or former smokers with current smokers in nine studies. ${ }^{21} 22$ 24-27 293135 In the seven studies measuring $\mathrm{FEV}_{1}$ decline, current smokers were observed to have a faster rate of decline..$^{21} 22$ 24-26 3135 In the three studies measuring FVC, smoking increased FVC decline. ${ }^{21} 24{ }^{35} \mathrm{FEV}_{1} / \mathrm{FVC}$ decline was greater in smokers than non-smokers in one study ${ }^{26}$ and $\mathrm{FEV}_{0.75}$ in another study. ${ }^{29}$

\section{Body mass index (BMI)}

Three studies reported the association of BMI with FEV change. In the study by Bartholomew and Knuiman, ${ }^{21}$ increased BMI significantly affected $\mathrm{FEV}_{1}$ decline ( $\mathrm{p}=0.008$ for females; $\mathrm{p}=0.007$ for males). However, an estimate for this association was not provided. In Triebner et $a l^{32}$ obese individuals reported greater declines of $\mathrm{FEV}_{1}$ (29 mL/year) and FVC (25 mL/year) compared with individuals with normal $\mathrm{BMI}\left(\mathrm{FEV}_{1} 22 \mathrm{~mL} /\right.$ year, $\mathrm{FVC}$ $10 \mathrm{~mL} /$ year). In Luoto et $a l^{35}$ having a BMI greater than 35 was significantly associated with a slower decline of $\mathrm{FEV}_{1}(32 \mathrm{~mL} /$ year compared with $46 \mathrm{~mL} /$ year, $\mathrm{p}=0.04)$, but it did not significantly affect FVC decline.

\section{Ethnicity}

Griffith $e$ t $a l^{24}$ was the only study that assessed ethnicity, specifically comparing African-American participants to white participants. We did not include the African-American cohort in our analysis as only two measurements were performed on this population. However, $\mathrm{FEV}_{1}$ and FVC declines were greater in whites compared with African-Americans.

\section{Systolic blood pressure}

Griffith $e t a l^{24}$ examined the correlation of systolic blood pressure greater than $160 \mathrm{~mm} \mathrm{Hg}$ with $\mathrm{FEV}_{1}$ and $\mathrm{FVC}$ decline and found that declines were on average $5.6 \mathrm{~mL} /$ year and $10.9 \mathrm{~mL} /$ year greater, respectively $(\mathrm{p}<0.01)$.

\section{Dust exposure}

Liao $e t a l^{26}$ explored the effects of dust exposure on $\mathrm{FEV}_{1}$ and $\mathrm{FEV}_{1} / \mathrm{FVC}$ decline. Participants with more dust exposure experienced a mean $\mathrm{FEV}_{1}$ decline that was $4.5 \mathrm{~mL} /$ 


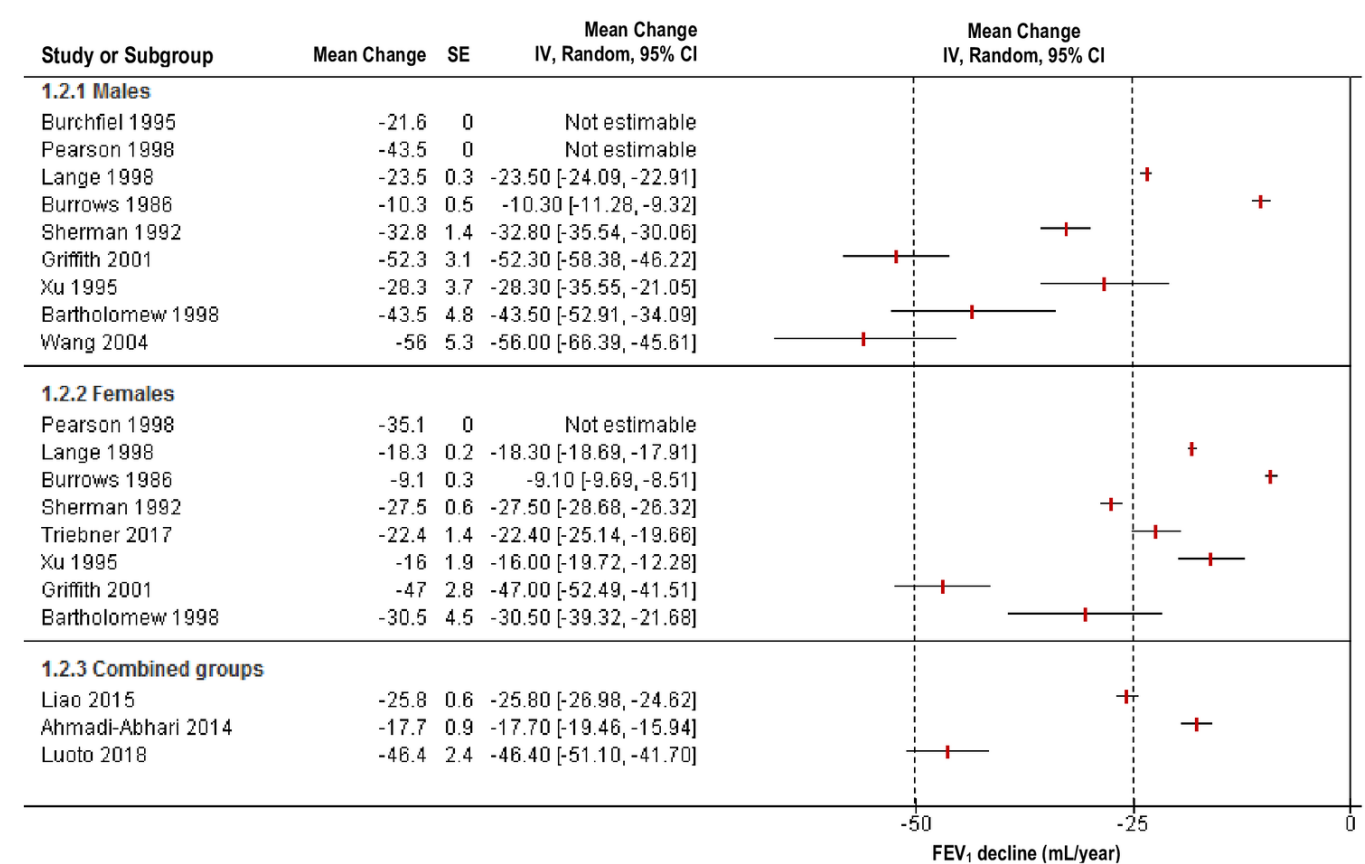

Figure 2 The rate of forced expiratory volume in $1 \mathrm{~s}\left(\mathrm{FEV}_{1}\right)$ decline in 13 study populations, grouped by sex.

year greater than participants with less dust exposure $(\mathrm{p}=0.007)$. Dust exposure did not significantly affect $\mathrm{FEV}_{1} / \mathrm{FVC}$ ratio decline, suggesting that $\mathrm{FVC}$ declined in parallel to FEV1.

\section{Menopausal status}

Triebner $e t a l^{32}$ reported that menopausal status affected the rate of decline, with rates of $\mathrm{FEV}_{1}$ decline on average $3.8 \mathrm{~mL} /$ year greater in perimenopausal women, and $5.2 \mathrm{~mL} /$ year greater in postmenopausal women. FVC decline was $10.2 \mathrm{~mL} /$ year greater in perimenopausal women and $12.5 \mathrm{~mL} /$ year greater in postmenopausal women, compared with premenopausal women.

\section{Risk of bias}

Risk of bias was determined using a modified version of the $\operatorname{NOS}^{19}$ (figures 5 and 6). No studies received low risk of bias in all domains, but four studies had a low risk of bias in all but one domain. ${ }^{232831}$ Thirteen studies (81\%) were graded as having low risk of bias for representativeness of the population. Six studies (38\%) were judged as low risk of bias on how they ascertained the age of the participants (from Medicare eligibility lists or health records). Four cohort studies $(25 \%)$ clearly demonstrated that pulmonary impairment was not present in participants at the beginning of the study. All studies (100\%) used a

Table 3 Age-specific lung function decline by decade of age as reported in four cohorts

\begin{tabular}{|c|c|c|c|c|c|c|}
\hline \multicolumn{7}{|c|}{ 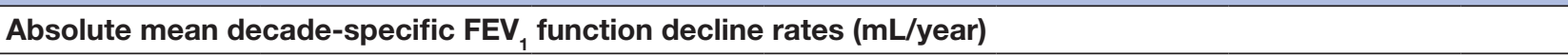 } \\
\hline \multirow[b]{2}{*}{ Study ID } & \multirow[b]{2}{*}{ Sample size (n) } & \multicolumn{5}{|c|}{ Baseline age (years) } \\
\hline & & $30-39$ & $40-49$ & $50-59$ & $60-69$ & $70-79$ \\
\hline Burrows, $1986^{23}$ & $\begin{array}{l}\text { Male } \\
(158)\end{array}$ & 2.83 & -3.01 & -8.85 & -14.69 & -20.53 \\
\hline \multirow[t]{2}{*}{ Pearson, $1998^{28}$} & $\begin{array}{l}\text { Female } \\
\text { (82) }\end{array}$ & -23.8 & -33.4 & -30 & -23.4 & -25.8 \\
\hline & $\begin{array}{l}\text { Male } \\
(91)\end{array}$ & -34 & -34 & -34 & -34 & -34 \\
\hline
\end{tabular}

The estimates from Burrows were derived from formulae modelling change in $\mathrm{FEV}_{1}$ with age. See online supplementary file 3 for calculations. *Estimates adjust for covariates including height and age.

†Includes participants aged $45-49$ years.

FEV1, forced expiratory volume in $1 \mathrm{~s}$. 


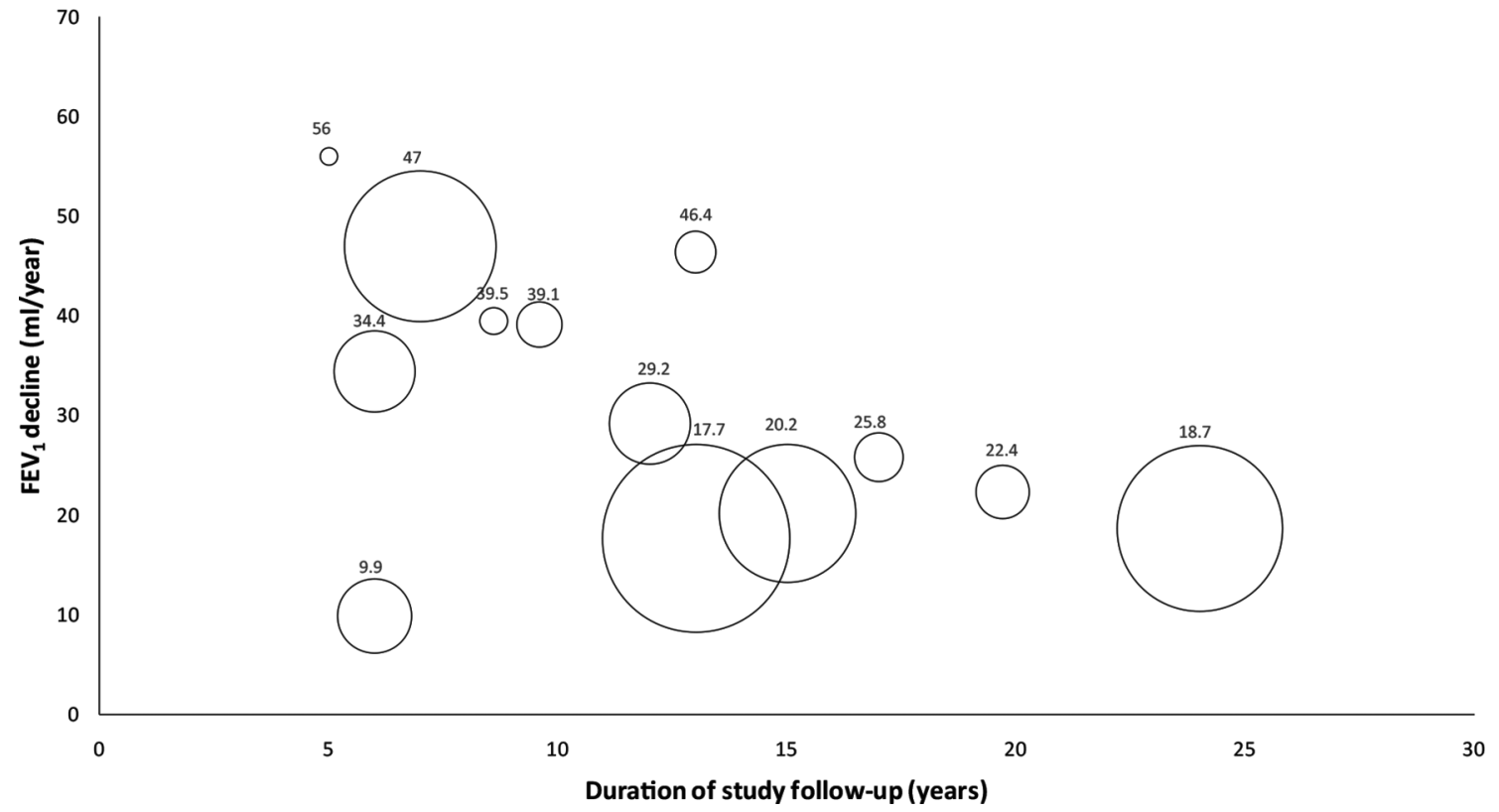

Figure 3 The rate of forced expiratory volume in $1 \mathrm{~s}\left(\mathrm{FEV}_{1}\right)$ decline in 13 study populations by years of follow-up. The size of the circle corresponds to individual study sample size.

spirometer to measure lung function which is a validated objective instrument. All studies (100\%) had adequate duration of follow-up (3years or longer). Eight studies $(50 \%)$ had a high risk of bias for having high attrition rates in their studies $(>20 \%)$.

\section{DISCUSSION}

\section{Statement of principal findings}

This systematic review of 16 prospective cohort studies conducted in 13 countries provides a summary of all the available evidence looking at lung function change with age. Lung function declines with age in normal, asymptomatic adults with higher rates of decline in absolute lung function parameters in men compared with women. However, the relative rates of decline from baseline between men and women do not differ significantly. The decline in absolute and relative lung function parameters may accelerate with age and is also exacerbated by smoking. We were unable to compare lung function decline rates of different ethnicities due to insufficient data. There was a paucity of longitudinal studies that reported changes in $\mathrm{FEV}_{1} / \mathrm{FVC}$ rather than reporting the two parameters separately.

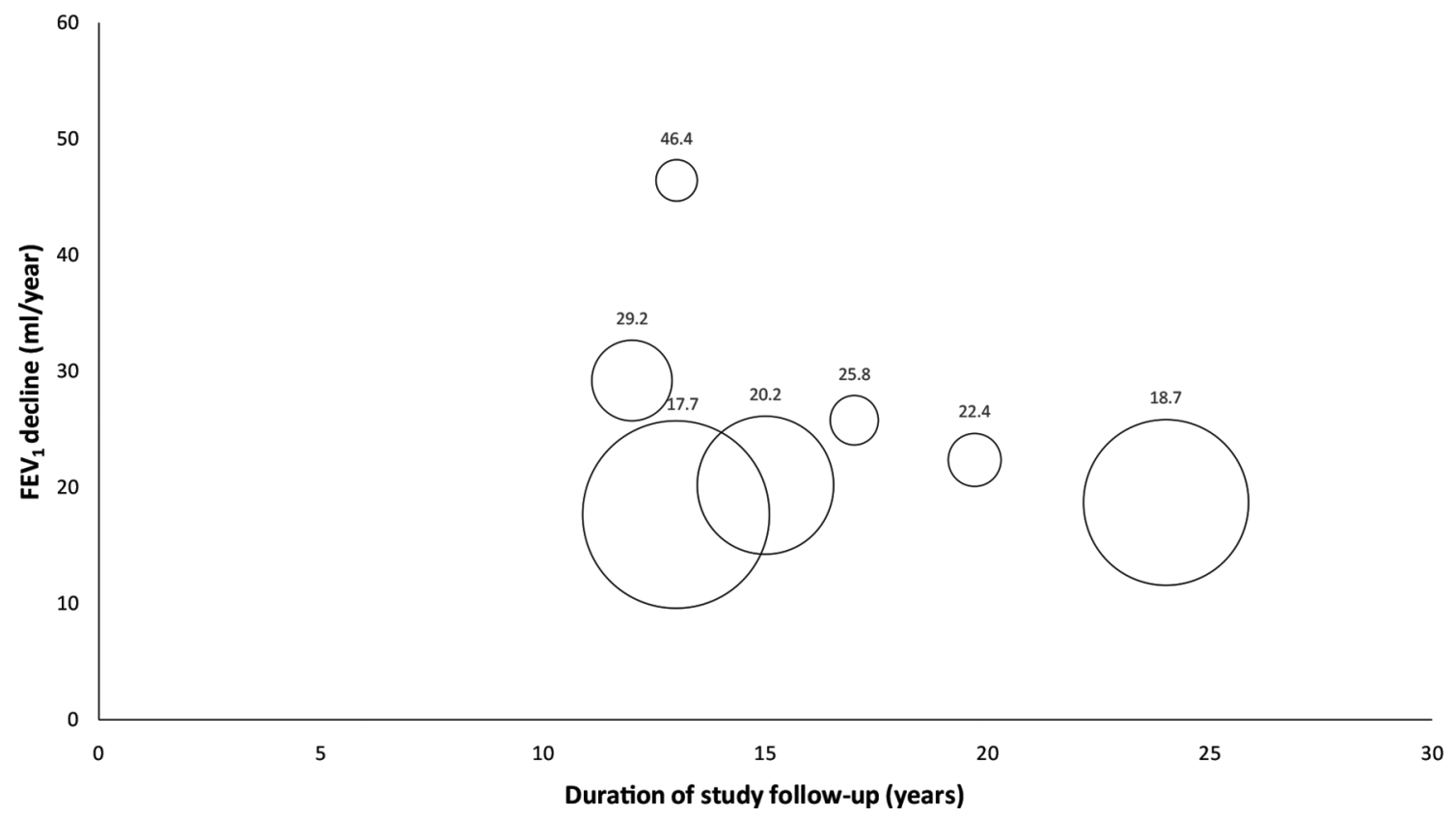

Figure 4 Sensitivity analysis, excluding studies with less than 10 years of follow-up. The size of the circle corresponds to individual study sample size. $\mathrm{FEV}_{1}$, forced expiratory volume in $1 \mathrm{~s}$. 


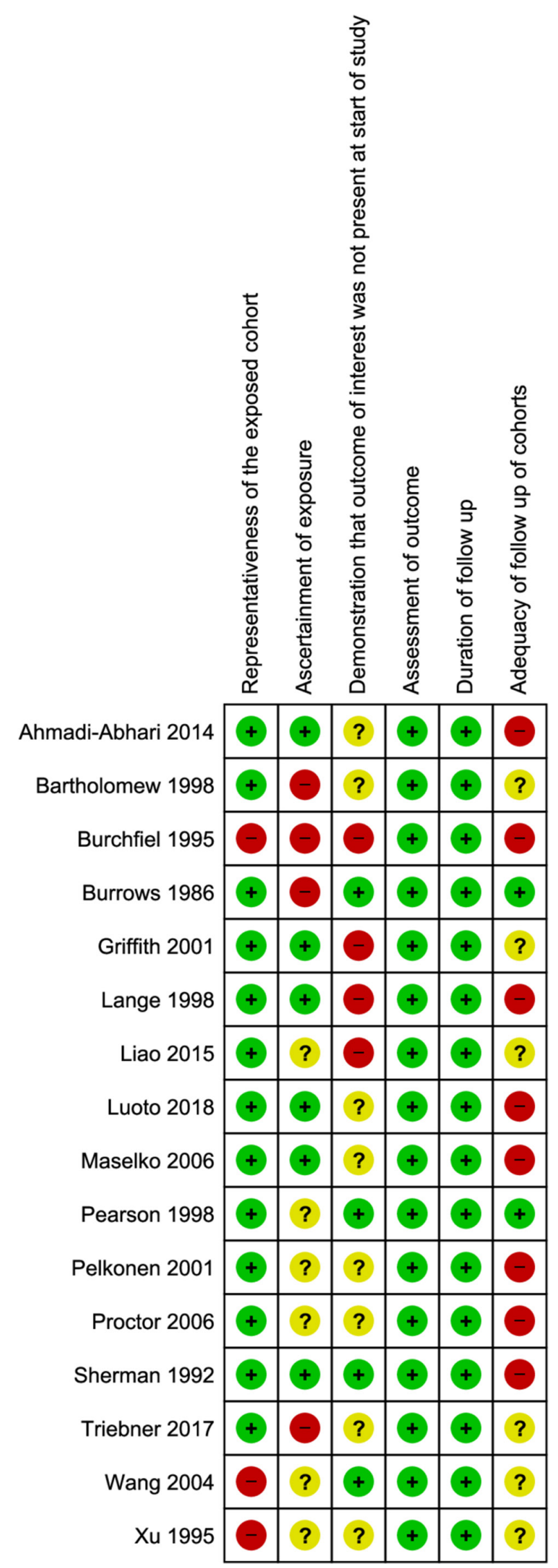

Figure 5 Risk of bias summary for prospective cohort studies estimating the rate of lung function decline with age, assessed using a modified form of the Newcastle-Ottawa Scale.

\section{Strengths and weaknesses of the study}

This systematic review examined all the available primary studies to allow an examination of the consistency of estimates of decline in $\mathrm{FEV}_{1}, \mathrm{FVC}, \mathrm{FEV}_{1} / \mathrm{FVC}$ ratio and PEFR. This review particularly focused on older adults; this group is relatively understudied and yet more prone to overdiagnosis and misdiagnosis. ${ }^{6818}$ While the majority of current prediction equations of lung function are based on cross-sectional studies, ${ }^{36-39}$ our review searched for longitudinal studies as they change in lung function may provide a complement to measurement at one time point in predicting future lung function. ${ }^{37}$ Our review included participants who were ageing normally, but may have had non-pulmonary comorbidities such as hypertension and diabetes mellitus. This enabled us to investigate a population that was more representative of a normal ageing population.

Our review has some limitations. We did not have access to unpublished individual participant data to allow the calculation of $\mathrm{FEV}_{1} / \mathrm{FVC}$ for the majority of studies, where this were not reported. Five studies separately measured changes in both $\mathrm{FEV}_{1}$ and $\mathrm{FVC}$, however is difficult to conclude whether the rate of decline in $\mathrm{FEV}_{1}$ and FVC is proportional. Out of the five studies that reported both FEV ${ }_{1}$ and FVC decline, two studies ${ }^{32}$ demonstrated that $\mathrm{FEV}_{1}$ declines faster than $\mathrm{FVC}$, but in the three remaining studies, ${ }^{20} 2124$ the FVC declined at a faster rate (see table 2). Longitudinal studies that specifically measure the $\mathrm{FEV}_{1} / \mathrm{FVC}$ would provide the most reliable measure of this decline. Individual patient data would also allow a more robust analysis of changes in lung function between individuals in the studies.

We were unable to pool the results due to significant heterogeneity across the populations. This review's findings are also limited by the quality of the included studies, all of which were judged moderate or low quality. Since this review is based on limited populations, the findings may not be generalisable to all individuals, especially those of non-Caucasian ethnicities or from less economically developed countries where smoking and air pollution may be more prevalent for example. The review's findings may underestimate lung function decline among asymptomatic people, as volunteer bias may be present with cohort studies where healthier individuals may be more likely to participate. Our study aimed to examine the rate of lung function change in the elderly group; however, the majority of included studies did not focus on this age group. COPD misdiagnosis particularly affects those older than 80 years of age; therefore, more studies are required in the elderly group.

Our review did not consider the extent of short-term within-person variation, or 'noise', in lung function measurements, which is likely to be considerable. ${ }^{40} 41$ Any observed change in measurement is a combination of the true change, or 'signal', and the random background 'noise'. The clinical utility of monitoring lung function to decide whether or not COPD is present is in part determined by the ratio of signal to noise in 


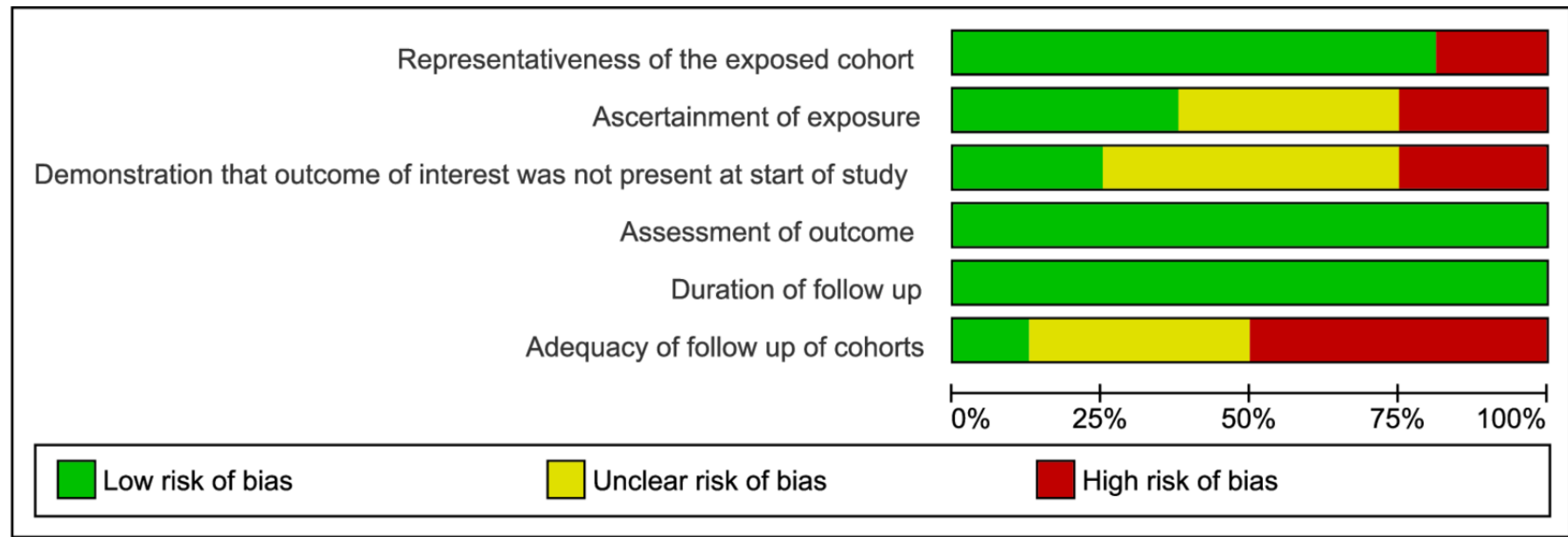

Figure 6 Graphical representation of the risk of bias in prospective cohort studies estimating the rate of lung function decline with age.

the measurements. ${ }^{42}$ Changes in measured lung function over a longer period of time may be more likely to indicate some true change rather than just background noise $^{43}$; therefore, we specified in our inclusion criteria that eligible studies should measure lung function on a minimum of three occasions.

We observed substantial heterogeneity across all the included studies and results. This may be due to inherent differences within the populations studied (including distribution of ages, proportion of men vs women and ethnicities) or the duration of follow-up, or that decline in normal healthy people may vary across individuals without causing disease. We explored differences in duration of follow-up as a potential source of heterogeneity in a sensitivity analysis excluding studies with less than 10 years of follow-up, but found that this did not change the median estimate substantially.

Quality of spirometry, as well as properly maintained and calibrated equipment, causing measurement error and contributing to the 'noise' in measurement discussed above, is likely to have contributed to variation in the results. Only nine of the included studies specifically reported that the spirometers used in their studies were calibrated and the measurements had to be acceptable and reproducible, following the American Thoracic Society guidelines on the standardisation of spirometry. ${ }^{44}$ Two studies used peak flow meters to measure PEFR. These instruments are well known to vary in consistency and accuracy. Maselko et al used a Mini-Wright meter, but the second study by Proctor et al did not specify which peak flow meter they used.

The majority of studies specified that they excluded patients with known disease or symptoms at the commencement of the study. However, most of the studies did not report whether any of the participants in their study sample developed symptoms or respiratory disease in the course of follow-up. Thus, undiagnosed COPD or other respiratory, cardiac, renal or other diseases that cause decline in lung function may have contributed to heterogeneity in the results.
Variation within the results may be also explained by the 'horse-racing effect', where an initially low FEV measurement may reflect a greater loss of function in the preceding years and hence predicts faster decline in subsequent years (just as the position of the horse in halfway through the race is related to its speed in the early part of the race and hence speed for the final part of the race).${ }^{45}{ }^{46}$ Regression to the mean, due to inclusion of people with randomly high (or low) measured lung function in the primary studies, may also have contributed to heterogeneity of the results. ${ }^{47} \mathrm{~A}$ simple way that primary studies may assess for a horse racing effect, while allowing for regression to the mean, is by constructing Bland-Altman plots of change versus mean $\mathrm{FEV}_{1}$ level $^{48}$ (or substituting PEFR for mean $\mathrm{FEV}_{1}$ as these are highly correlated). ${ }^{49}$

\section{Comparison with previous research}

To date, there have been no systematic reviews or meta-analyses examining the rate of lung function decline with age to assess the potential impact of the fixed threshold on COPD misdiagnosis. Cross-sectional studies have compared people diagnosed with COPD using a fixed threshold and the LLN definition, reporting that the GOLD criteria leads to misdiagnosis of COPD. ${ }^{5-8} \mathrm{~A}^{50}$ prospective cohort study found that the fixed threshold of the GOLD criteria overdiagnosed a large proportion of elderly people over the age of 70 years, and the LLN criteria tended to underdiagnose COPD, when compared with the reference standard which consisted of an expert panel who used all available diagnostic information including spirometry. ${ }^{18}$

\section{Meaning of the study: possible explanations and implications} for clinicians and policy-makers

This review has found that lung function declines with age in all studied populations. The rate of decline appears to accelerate with age, and age-specific estimates of $\mathrm{FEV}_{1}, \mathrm{FVC}_{\text {and }} \mathrm{FEV}_{1} / \mathrm{FVC}$ ratio may be more appropriate for the diagnosis of COPD than the fixed threshold 
currently used across all ages. Currently, prediction equations for calculating mean lung function values as well as the lower limit of normal (LLN) for all ages are based on data from cross-sectional studies; however; it is argued that this is problematic as they do not factor in the important dimension of time. ${ }^{51}{ }^{52}$ Spirometers used in practice commonly derive their reference values from the National Health and Nutrition Examination Survey (NHANES), a cross-sectional study which was conducted in the USA between 1988 and 1994. Though the predicted values do reflect a decline in $\mathrm{FEV}_{1}$ and $\mathrm{FEV}_{1} / \mathrm{FVC}$ with age, these decline rates may not be as reliable as the estimates from longitudinal studies included in our review. According to the NHANES III, the median rate of $\mathrm{FEV}_{1}$ decline for a Caucasian male with an average height of $1.75 \mathrm{~m}$ aged between 30 and 80 is $32 \mathrm{~mL} /$ year and a female with an average height of $1.6 \mathrm{~m}$ has an $\mathrm{FEV}_{1}$ that declines a median of $25 \mathrm{~mL} /$ year. Both of these estimates are lower than the median $\mathrm{FEV}_{1}$ decline of the studies in our review, which was $43.5 \mathrm{~mL} /$ year and $30.5 \mathrm{~mL} /$ year for men and women, respectively. Therefore, the predicted age-specific lung function used in spirometers may often mislabel people as having abnormal lung function when they are actually within normal limits. ${ }^{53}$ More reliable age-specific estimates and prediction equations are required.

Clinicians need to consider whether 'abnormal' spirometry results may in fact represent normal ageing. This is especially true for making a formal diagnosis of COPD. If a patient is symptomatic and has airflow obstruction as defined by GOLD criteria, it may be necessary to consider alternative diagnoses such as a dyspnoea of cardiac origin. One proposal for identifying individuals who are experiencing greater loss of lung function than expected is to develop 'decline charts' that predict $\mathrm{FEV}_{1}$ or $\mathrm{FEV}_{1}$ / FVC loss for different ages. This can allow clinicians to monitor lung function over time and assess whether individuals are tracking along expected decline curves. These would also need to account for noise in measurement.

Future research should focus on conducting long-term longitudinal studies in less-studied populations, with emphasis on older adults. These studies should examine the rates of decline in people who eventually become symptomatic or develop disease. This information can guide clinicians to predict what rate of lung function decline may be a prognostic indicator of COPD onset and progression. Further well-designed prospective studies that investigate changes in $\mathrm{FEV}_{1} / \mathrm{FVC}$ may allow for the development of algorithms that predict individuals' expected lung function over time according to their sex, smoking history, age, BMI and ethnicity. The observed change in lung function parameters might then be compared with the expected change to help the clinician determine whether this is extreme enough to warrant diagnosis of disease.

Acknowledgements The authors thank Mr Justin Clark for his assistance with the literature search, Ms Mari Tashiro for her help with the translation of Japanese studies, Dr Mark Jones for his advice on statistical analysis and Dr Claudia Dobler for her specialist input on this review.

Contributors ETT was involved with devising the review methods, conducting electronic searches, screening of abstracts, data extraction, data analysis and interpretation and co-drafting of the review. MG was involved with devising the review methods, screening of abstracts, data extraction, data analysis and interpretation and co-drafting the review. KJLB was involved with devising the review methods, data analysis and interpretation and co-drafting the review. SES was involved with devising the review methods, data analysis and interpretation and co-drafting the review. PG was involved with devising the review methods, data analysis and interpretation and co-drafting the review.

Funding KJLB and PG have received funding from the Australian National Health and Medical Research Council (Centre for Research Excellence Grant No 1104136, Australia Fellowship No 527500 and Program Grant No 633003). The funders had no role in design and conduct of the study; collection, management, analysis and interpretation of the data; and preparation, review or approval of the manuscript.

Competing interests None declared.

Patient consent for publication Not required.

Provenance and peer review Not commissioned; externally peer reviewed.

Data sharing statement № additional data are available.

Author note This manuscript was prepared in accordance with the PRISMA statement and the MOOSE reporting guidelines.

Open access This is an open access article distributed in accordance with the Creative Commons Attribution Non Commercial (CC BY-NC 4.0) license, which permits others to distribute, remix, adapt, build upon this work non-commercially, and license their derivative works on different terms, provided the original work is properly cited, appropriate credit is given, any changes made indicated, and the use is non-commercial. See: http://creativecommons.org/licenses/by-nc/4.0/.

\section{REFERENCES}

1. World Health Organization. Chronic obstructive pulmonary disease (COPD). 2017 http://www.who.int/news-room/fact-sheets/detail/ chronic-obstructive-pulmonary-disease-(copd) (accessed 5 Aug 2018).

2. National Institute for Health and Care Excellence. Chronic obstructive pulmonary disease in over 16s: diagnosis and management. 2010 https://www.nice.org.uk/guidance/cg101 (accessed 5 Aug 2018).

3. Lung Foundation Australia. The COPD-X Plan: Australian and New Zealand Guidelines for the management of Chronic Obstructive Pulmonary disease 2018. 2018 https://copdx.org.au/wp-content/ uploads/2018/06/COPDX-V2-53-March-2018_2.pdf (accessed 5 Aug 2018).

4. Qaseem A, Wilt TJ, Weinberger SE, et al. Diagnosis and management of stable chronic obstructive pulmonary disease: a clinical practice guideline update from the American College of Physicians, American College of Chest Physicians, American Thoracic Society, and European Respiratory Society. Ann Intern Med 2011;155:179-91.

5. Schermer T, Smeele I, Thoonen B, et al. Current clinical guideline definitions for airflow obstruction leads to substantial overdiagnosis of COPD in primary care. Eur Respir J 2008;52(2.

6. Swanney MP, Ruppel G, Enright PL, et al. Using the lower limit of normal for the FEV1/FVC ratio reduces the misclassification of airway obstruction. Thorax 2008;63:1046-51.

7. Shirtcliffe P, Weatherall M, Marsh S, et al. COPD prevalence in a random population survey: a matter of definition. Eur Respir $J$ 2007;30:232-9.

8. Hardie JA, Buist AS, Vollmer WM, et al. Risk of over-diagnosis of COPD in asymptomatic elderly never-smokers. Eur Respir $J$ 2002;20:1117-22.

9. Medbø A, Melbye H. Lung function testing in the elderly--can we still use FEV1/FVC $<70 \%$ as a criterion of COPD? Respir Med 2007;101:1097-105 https://doi.org/.

10. Miller MR, Levy ML. Chronic obstructive pulmonary disease: missed diagnosis versus misdiagnosis. BMJ 2015;351:h3021.

11. Morris JF, Temple WP, Koski A. Normal values for the ratio of onesecond forced expiratory volume to forced vital capacity. Am Rev Respir Dis 1973;108:1000-3

12. Hankinson JL, Odencrantz JR, Fedan KB. Spirometric reference values from a sample of the general U.S. population. Am J Respir Crit Care Med 1999;159:179-87. 
13. Glindmeyer HW, Lefante JJ, McColloster C, et al. Blue-collar normative spirometric values for Caucasian and African-American men and women aged 18 to 65 . Am J Respir Crit Care Med 1995;151:412-22 https://doi.org/.

14. Bossé R, Sparrow D, Garvey AJ, et al. Cigarette smoking, aging, and decline in pulmonary function: a longitudinal study. Arch Environ Health 1980;35:247-52.

15. Huhti E. Ikkala J. A 10-year follow-up study of respiratory symptoms and ventilatory function in a middle-age rural population. Eur $J$ Resp Dis 1980;61:33-45.

16. Global Initiative for Chronic Obstructive Lung Disease. Pocket Guide to COPD Diagnosis, Management and Prevention: a guide for health care professionals. $2018 \mathrm{https}$ //goldcopd.org/wp-content/uploads/ 2018/02/WMS-GOLD-2018-Feb-Final-to-print-v2.pdf (accessed 5 Aug 2018)

17. van Dijk W, Tan W, Li P, et al. Clinical relevance of fixed ratio vs lower limit of normal of FEV1/FVC in COPD: patient-reported outcomes from the CanCOLD cohort. Ann Fam Med 2015;13:41-8.

18. Güder G, Brenner S, Angermann CE, et al. "GOLD or lower limit of normal definition? A comparison with expert-based diagnosis of chronic obstructive pulmonary disease in a prospective cohortstudy". Respir Res 2012;13:13.

19. Wells G, Shea B, O'Connell D, et al. The Newcastle-Ottawa Scale (NOS) for assessing the quality of nonrandomised studies in metaanalyses: The Ottawa Hospital. http://www.ohri.ca/programs/clinical epidemiology/oxford.asp (accessed 12 Aug 2018).

20. Ahmadi-Abhari S, Kaptoge S, Luben RN, et al. Longitudinal association of $\mathrm{C}$-reactive protein and lung function over 13 years: The EPIC-Norfolk study. Am J Epidemiol 2014;179:48-56.

21. Bartholomew HC, Knuiman MW. Longitudinal analysis of the effect of smoking cessation on cardiovascular risk factors in a community sample: the Busselton Study. J Cardiovasc Risk 1998;5:263-71.

22. Burchfiel CM, Marcus EB, Curb JD, et al. Effects of smoking and smoking cessation on longitudinal decline in pulmonary function. Am $J$ Respir Crit Care Med 1995;151:1778-85.

23. Burrows $B$, Lebowitz MD, Camilli AE, et al. Longitudinal changes in forced expiratory volume in one second in adults. Methodologic considerations and findings in healthy nonsmokers. Am Rev Respir Dis 1986;133:974-80.

24. Griffith KA, Sherrill DL, Siegel EM, et al. Predictors of loss of lung function in the elderly: the Cardiovascular Health Study. Am J Respir Crit Care Med 2001:163:61-8.

25. Lange P, Parner J, Vestbo J, et al. A 15-year follow-up study of ventilatory function in adults with asthma. $N$ Engl $J$ Med 1998;339:1194-200.

26. Liao SY, Lin X, Christiani DC. Occupational exposures and longitudinal lung function decline. Am J Ind Med 2015;58:14-20.

27. Maselko J, Kubzansky L, Kawachi I, et al. Religious service attendance and decline in pulmonary function in a high-functioning elderly cohort. Ann Behav Med 2006;32:245-53.

28. Pearson JD, Kao SY, Brant LJ, et al. Longitudinal change in forced expiratory volume in healthy, non-smoking men and women: The Baltimore Longitudinal Study of Aging. Am J Hum Biol 1998;10:471-81.

29. Pelkonen M, Notkola IL, Tukiainen $\mathrm{H}$, et al. Smoking cessation, decline in pulmonary function and total mortality: a 30 year follow up study among the Finnish cohorts of the Seven Countries Study. Thorax 2001:56:703-7.

30. Proctor DN, Fauth EB, Hoffman L, et al. Longitudinal changes in physical functional performance among the oldest old: insight from a study of Swedish twins. Aging Clin Exp Res 2006;18:517-30.
31. Sherman $\mathrm{CB}, \mathrm{Xu} X$, Speizer FE, et al. Longitudinal lung function decline in subjects with respiratory symptoms. Am Rev Respir Dis 1992;146:855-9.

32. Triebner K, Matulonga B, Johannessen A, et al. Menopause is associated with accelerated lung function decline. Am J Respir Crit Care Med 2017;195:1058-65.

33. Wang ML, Petsonk EL. Repeated measures of FEV1 over six to twelve months: what change is abnormal? J Occup Environ Med 2004; $46: 591-5$

34. Xu X, Laird N, Dockery DW, et al. Age, period, and cohort effects on pulmonary function in a 24-year longitudinal study. Am J Epidemiol 1995;141:554-66.

35. Luoto J, Pihlsgard M, Wollmer P, et al. Relative and absolute lung function change in a general population aged 60-102 years. Eur Respir J 2018.

36. Cherniack RM, Raber MB. Normal standards for ventilatory function using an automated wedge spirometer. Am Rev Respir Dis 1972;106:38-46.

37. Lung function testing: selection of reference values and interpretative strategies. American Thoracic Society. Am Rev Respir Dis 1991;144:1202-18.

38. Morris JF, Koski A, Johnson LC. Spirometric standards for healthy nonsmoking adults. Am Rev Respir Dis 1971;103:57-67.

39. Paoletti P, Pistelli G, Fazzi P, et al. Reference values for vital capacity and flow-volume curves from a general population study. Bull Eur Physiopathol Respir 1986;22:451-9.

40. Macintyre N. Finding signals amidst the noise in pulmonary function testing. Chest 2007;132:367-8.

41. Becklake MR, White N. Sources of variation in spirometric measurements. Identifying the signal and dealing with noise. Occup Med 1993;8:241-64.

42. Bell KJ, Glasziou PP, Hayen A, et al. Criteria for monitoring tests were described: validity, responsiveness, detectability of long-term change, and practicality. J Clin Epidemiol 2014;67:152-9.

43. Pellegrino R, Viegi G, Brusasco V, et al. Interpretative strategies for lung function tests. Eur Respir J 2005;26:948-68.

44. Miller M, Hankinson J, Brusasco V, et al. Standardisation of spirometry. Eur J Resp 2005;26:319-38.

45. Fletcher C, Peto R, Tinker C, et al. The natural history of chronic bronchitis and emphysema. Oxford University Press: Oxford, 1970.

46. Peto R. The horse-racing effect. Lancet 1981;2:467-8.

47. Bland JM, Altman DG. Statistics Notes: Some examples of regression towards the mean. BMJ 1994;309:780.

48. Bland JM, Altman DG. Statistics Notes: Measurement error proportional to the mean. BMJ 1996;313:106.

49. Gautrin D, D'Aquino LC, Gagnon G, et al. Comparison between peak expiratory flow rates (PEFR) and FEV1 in the monitoring of asthmatic subjects at an outpatient clinic. Chest 1994;106:1419-26.

50. Wang $\mathrm{Y}, \mathrm{Xiao} \mathrm{W}, \mathrm{Ma} \mathrm{DD}$, et al. Predicted lower limit of normal reduces misclassification risk of airflow limitation in asymptomatic elderly never-smokers. Chin Med J 2013;126:3486-92.

51. Brändli $\mathrm{O}$, Schindler $\mathrm{C}$, Künzli $\mathrm{N}$, et al. Lung function in healthy never smoking adults: reference values and lower limits of normal of a Swiss population. Thorax 1996;51:277-83.

52. Marks GB. Are reference equations for spirometry an appropriate criterion for diagnosing disease and predicting prognosis? Thorax 2012;67:85-7.

53. Vitalograph. NHANES - normal values. 2019 https://vitalograph.com/ resources/nhanes-normal-values (accessed 9 Feb 2019). 